\title{
Mechanical and tribological studies of polymer hybrid nanocomposites with nano reinforcements
}

\author{
D LINGARAJU*, K RAMJI ${ }^{\dagger}$, M PRAMILA DEVI ${ }^{\dagger}$ and U RAJYA LAKSHMI \\ G.V.P. College of Engineering, Madhurawada, Vishakapatnam, India \\ ${ }^{\dagger}$ Mechanical Department, Andhra University, Vishakapatnam, India
}

MS received 19 September 2009; revised 28 January 2010

\begin{abstract}
Developments of nanoparticle reinforced plastics are of growing interest towards the emergence of new materials which enhance optimal utilization of natural resources and particularly of renewable resources. The effects of nanoparticles as fillers in glass-epoxy composite systems on the mechanical and tribological properties have been discussed in this article. The mechanical properties such as tensile strength, impact strength, flexural strength, and hardness have been studied in accordance with ASTM standards. The composites employed in the study have been fabricated using hand lay-up technique. By varying notch radius impact strength is studied. The clay and silica used in the present system were treated with 3-aminopropyltriethoxysilane. The effect of variants in sliding speed, time and applied load on the wear behavior of polymer nanocomposites is studied by measuring the weight changes and observing the surface features using scanning electron microscope. In the experiments with wear test pin having flat face in contact with hardening rotating steel disc, sliding speed, time and loads in the range of 640-1000 RPM, 300-900 s and 5-25 $\mathrm{N}$ respectively was used. It is observed that wear rate increases with increasing applied load, time and sliding speeds.
\end{abstract}

Keywords. Halloysite clay; silica; sonication; pin-on-disk; tensile strength; impact strength.

\section{Introduction}

Tribology is a science that deals with design, friction, wear and lubricating surfaces in relative motion (Friedrich et al 1995). Polymer nanocomposites based on layered clays have attracted a great deal of interest because they exhibit remarkable improvement of physical properties when compared with those of pure polymer or conventional composites. These improvements include increased strength, toughness, heat resistance and fire retardancy, and decreased gas permeability. Three main types of structures can be obtained when layered clay is associated with a polymer: (i) a phase-separated structure, (ii) an intercalated structure and (iii) an exfoliated or delaminated structure (Maiti et al 2002; Ray et al 2002a, b; Yamada et al 2002; Okamoto et al 2003).

The unprecedented mechanical properties of nylon 6clay nanocomposite synthesized by in-situ polymerization were first demonstrated by researchers at the Toyota central research laboratories. Such nanocomposites exhibit improvement to the extent of $40 \%$ in tensile strength, $60 \%$ in flexural strength and $68 \%$ in tensile modulus, and $126 \%$ in flexural modulus (Ojima et al 1993).

*Author for correspondence (dlraju@gmail.com)
For tribological loaded components, the coefficient of friction, the mechanical load carrying capacity, and the wear rate of the materials determine their acceptability for industrial applications. Polymer based composite materials are the ones employed in tribological applications owing to their ever increasing demand in terms of stability at higher loads, temperatures, better lubrication and wear properties (Vinson and Chou 1975; Biswas and Vijayan 1992).

Epoxy resins are the preferred matrix material since they possess better mechanical and thermal properties. Further, they wet many substrate materials and absorb less moisture. The other advantage worth mentioning is that they possess excellent chemical resistance and good electrical properties (Mallick 1993). The wear of polymeric composites with different reinforcements has been the topic of investigation in recent times (Chang 1983; Lhymn 1987; Bijwe et al 1989; Viswanath et al 1992; Tripaty and Furay 1993; EI-Sayed et al 1995; Kishore and Sethuramu 1999). Particles added to polymers have been proven to be effective in reducing the coefficient of friction and wear rate of composites. The use of $\mathrm{SiC}$ as a filler material is known to improve the mechanical and tribological properties of metal-matrix composites (Ferhat and Mehmet 2004). Figure 1 represents three main types of composites for layered silicate materials. When the polymer is unable to intercalate (or penetrate) between 
the silicate sheets, a phase-separated composite is obtained and the properties stay in the same range as those for traditional microcomposites. In an intercalated structure, where a single extended polymer chain can penetrate between the silicate layers, a well-ordered multilayer morphology results with alternating polymeric and inorganic layers. An exfoliated or delaminated structure is obtained when the silicate layers are completely and uniformly dispersed in a continuous polymer matrix. When the filler has nanometer thickness and high aspect ratio (30-1000) plate-like structure, it is classified as layered nanomaterial (such as an organosilicate) (Alexandre and Dubois 2000). In general, nanomaterials provide reinforcing efficiency because of their high aspect ratios (Luo and Daniel 2003).

The properties of a nanocomposite are greatly influenced by the size of its component phases and the degree of mixing between the two phases. Significant differences in composite properties can be obtained depending on the nature of the components (layered silicate or nanofiber, cation exchange capacity and polymer matrix) used and the method of preparation (Park et al 2001).

The effect of clay addition improves the mechanical properties of epoxy polymer and glass fiber-reinforced epoxy-clay hybrid composites. The clays used in the present system were alkyl ammonium treated montmorillonite (MMT) based organoclay (OC) and unmodified MMT clay (UC). The addition of OC increases the thermal properties of epoxy-glass fiber more than that of UC filled hybrids (Velmurugan 2009).

To increase reactivity of nano-silica, the nanoparticles were pretreated by the silane coupling agent, c-methacryloxypropyl trimethoxy silane that introduces double bonds onto their surfaces (denoted as $\mathrm{SiO}_{2}$-g-silane). The amount of the coupling agent attached to nano- $\mathrm{SiO}_{2}$ surface is fixed at $6.62 \mathrm{wt} \%$ in the subsequent study, as confirmed by TGA measurement. In addition, nano-silica particles are well dispersed and interconnected in the

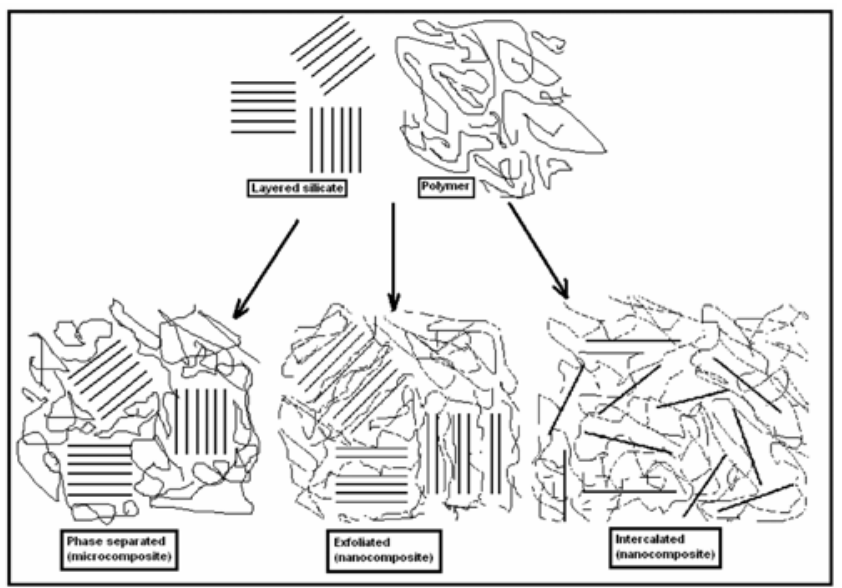

Figure 1. Scheme of three main types of layered silicates in polymer matrix. networks throughout the poly propylene matrix. Owing to the microstructure slippage, realignment and motion of polymer chains can be greatly obstructed. As a result, creep resistance of the PP based nanocomposites becomes much superior to those of untreated nano- $\mathrm{SiO}_{2} / \mathrm{PP}$ and also the unfilled version (Zhou et al 2007).

\section{Experimental}

\subsection{Materials and their characterization}

The matrix used in the present study was an epoxy resin (LY556) system from ECMAS Pvt. Ltd, Hyderabad, an araldite hardener (HY951) mixed in proportions of 100 : 12 from ECMAS Pvt. Ltd, Hyderabad.

The reinforcing clay nanoparticle Halloysite nano tubler (HNT) clay was from Sigma Aldich, Germany and silica from CHEMAPOL India Ltd. These are organically modified with a 3-aminopropyltriethoxysilane by sonication process. Woven roving glass fiber mat is from SaintGobain-Vetrotex India Ltd.

\subsection{Synthesis of silica by high energy ball milling}

Mechanical alloying is a process involving repeated cold welding, fracturing and re-welding of powder particles in a high-energy ball mill (Suryanarayana 2004). Such a process can result in the formation of an alloy with nanometer-sized grains. During the mechanical alloying process, the powder particles are periodically trapped between colliding balls and are plastically deformed. Such a feature occurs by the generation of a large number of dislocations as well as other lattice defects. The ball collisions cause fracturing and cold welding of the elementary particles, forming clean interfaces at the atomic scale. This leads to an increase in the interface number while the sizes of the components' area decrease from millimeter to sub micrometer dimensions. Concurrent to this decrease of the elementary distribution, some crystalline and nanocrystalline intermediate phases are produced inside the particles involving chemical changes. Different types of materials including ceramic, metallic, polymer and composites are synthesized by ball milling. A large number of phases can be formed depending on each alloy system.

There are different machines available for mechanical alloying. These differ in capacity, speed of operation, efficiency of milling and additional arrangement for cooling, and heating among others. The PM 100 is a benchtop model with 1 grinding station for grinding jars with a nominal volume of 12 to $500 \mathrm{ml}$. This type of ball milling equipment is used to produce less than hundred grams of powder. Its name represents the planet-like movement of its jar on a rotating support disk. The jar rotates around its own axes. 

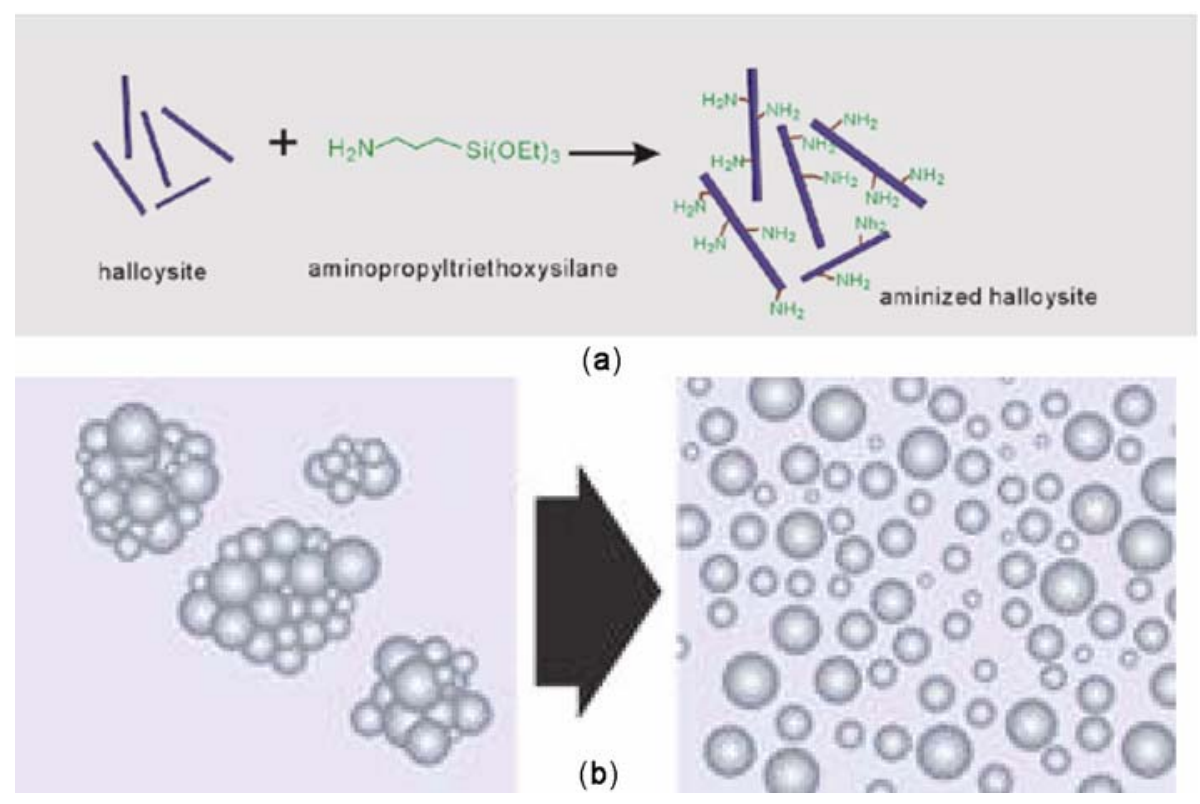

Figure 2. (a) Functionalization of Halloysite clay with 3-aminopropltriethoxysilane, (b) Dispersion of silica particles in epoxy (26-28).

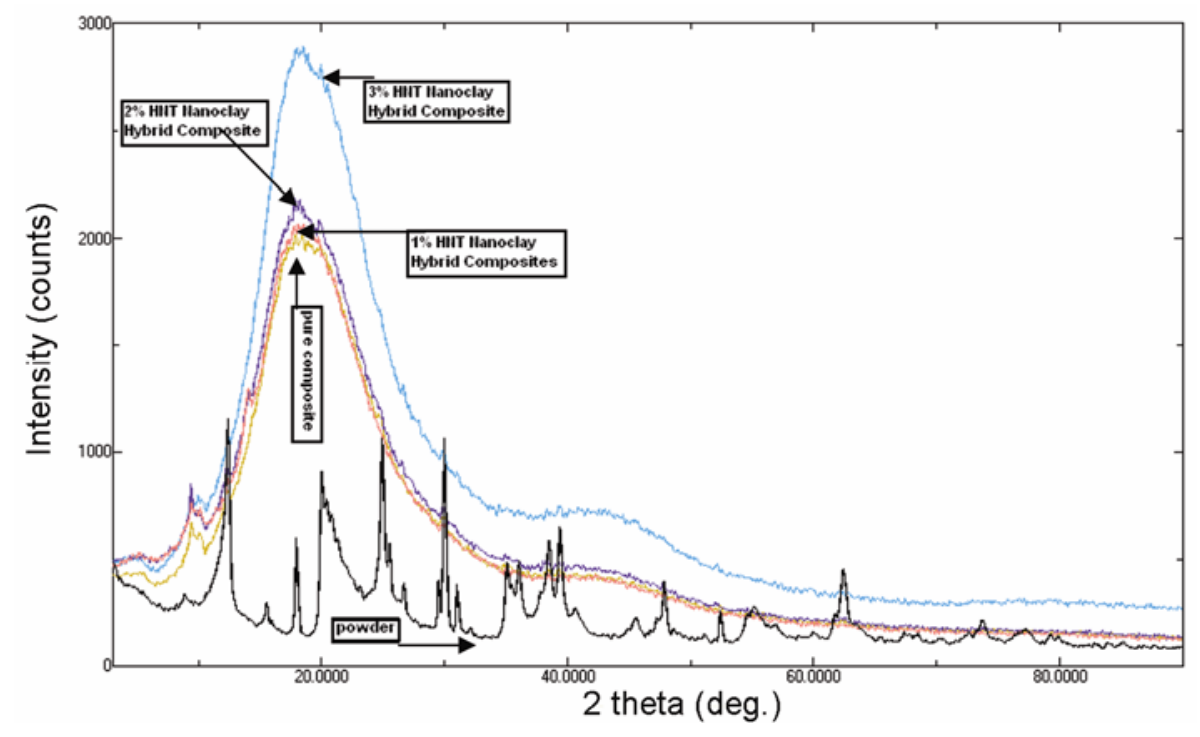

Figure 3. XRD multiple pattern of powder/ clay hybrid composites with pure, 1, 2, $3 \mathrm{wt} \%$.

\subsection{Functionalization of Halloysite clay and silica}

Improvements in mechanical properties are dependent upon the nature of the interactions between the matrix and the filler (intercalative versus exfoliated structures, ionic interactions as determined by the structure of the alkylammonium salt, the polarity of the polymer).

A 3-aminopropyltriethoxysilane was used to disperse/ exfoliate the clay nanoparticles in an epoxy matrix. The compounding process was carried out with varying clay contents ( 1,2 and $3 \mathrm{wt} \%)$. The technique was found highly efficient and environment friendly in achieving high levels of exfoliation and dispersion within a short period of time.

The improvement of properties of Halloysite clay nanocomposites is directly related to the complete exfoliation of silicate layers in the polymer matrix. However, a processing technique that produces complete exfoliation is still a technical challenge. This may be due to the high viscosity of the resin and the strong tendency of Halloysite clay nanoparticles to agglomerate.

Halloysite is a naturally occurring aluminosilicate nanotube. The two-layer halloysite tubes are chemically similar to kaoline and have average dimensions of 
$30 \eta \mathrm{m} \times 4 \mu \mathrm{m}$ comparable to carbon nanotubes. Halloysite tubes are hollow and can be used for controlled delivery and release of drugs as well as nanocomposite and rheology modification applications.

Silica is used in various industries for its abrasion resistance, electrical insulation and high thermal stability. Ultrasonic dispersing helps to use the potential of silica by improving the dispersion quality. Silica is available in a wide range of hydrophilic and hydrophobic forms and is typically used in extremely fine particle size. Typically silica is not well dispersed after wetting. It also adds a lot of micro bubbles to the product formulation (Kuldiloke 2002; Vaia et al 1993).

For most silica applications, a good and uniform dispersion is important. In particular, when being used in coatings and lacquers to improve scratch resistance, the silica particles need to be small enough not to interfere with the visible light to avoid haze and maintain

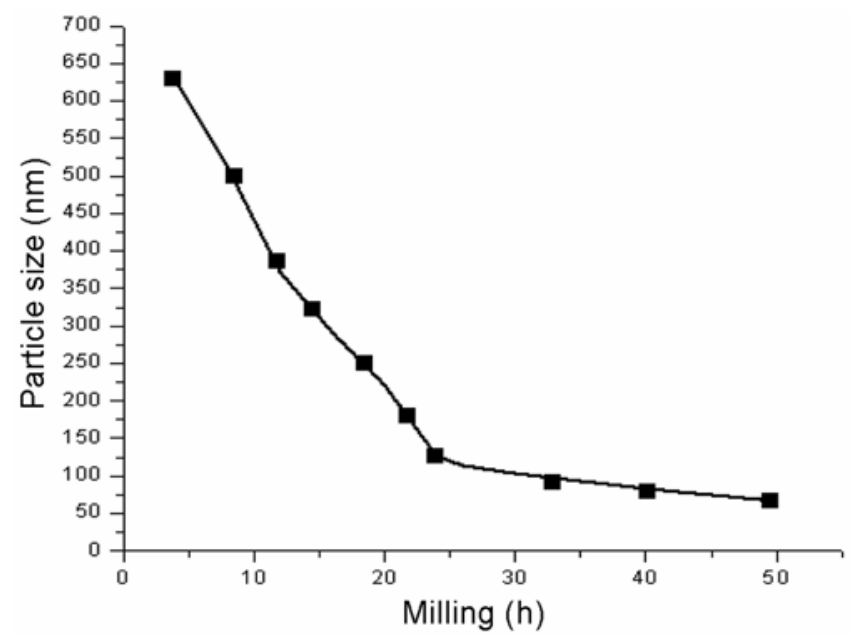

Figure 4. Particle size vs milling hours for 200 mesh silica.

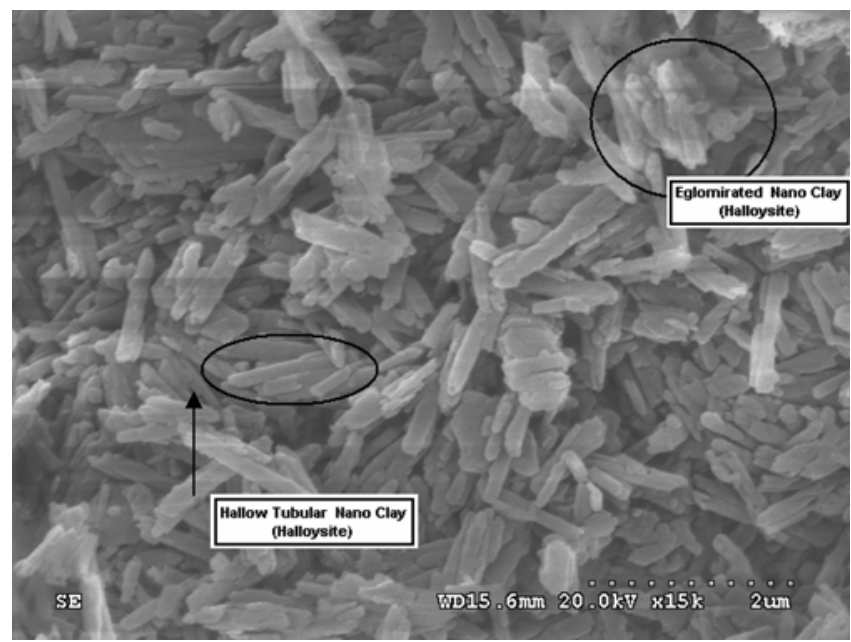

Figure 5. SEM photo of nanoclay (hollow nano tubes). transparency. For most coatings silica need to be smaller than $40 \mathrm{~nm}$ to fulfill this requirement. For some other applications, particle agglomeration hinders each individual silica particle to interact with the surrounding media. Ultrasonic processing has been proven to be more effective in the dispersing of silica than other high-shear mixing methods. In this study, an ultra sonicator, shown in figure 2, was used to disperse and exfoliate the treated clay nanoparticles in the epoxy matrix.

\subsection{Synthesis of hybrid nanocomposite}

The synthesis of glass fiber reinforced epoxy with particle reinforced hybrids consists of mixing of epoxy resin with nanoparticles and woven rove glass fibers by the hand-lay up process. $50 \mathrm{wt} \%$ of fiber and $50 \mathrm{wt} \%$ of epoxy resin are used for preparation of hybrid composite. The laminates are cured at room temperature and left in the mould for $24 \mathrm{~h}$ for complete curing.

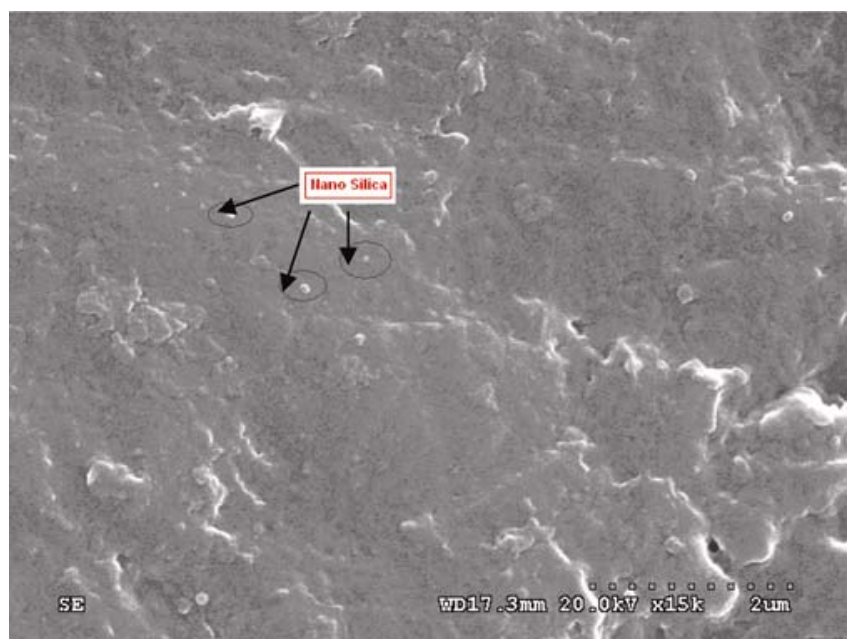

Figure 6. SEM photo of polymer-silica nanocomposites.

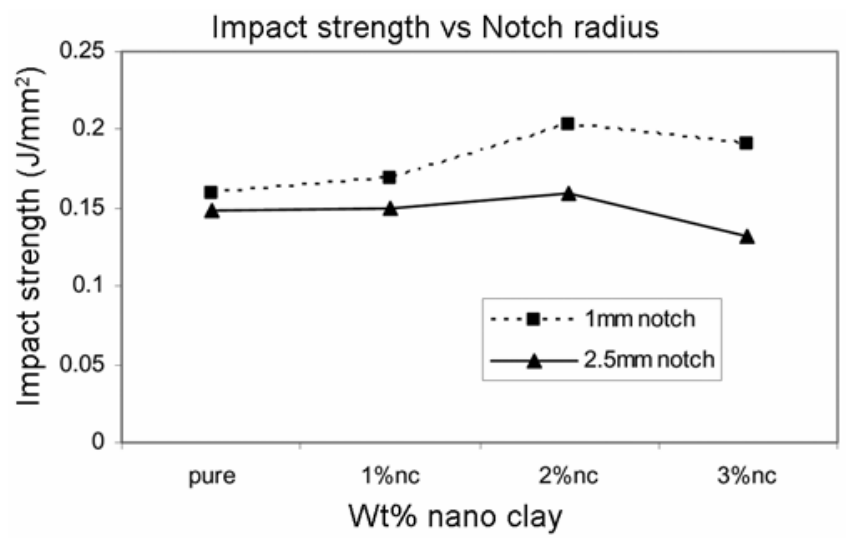

Figure 7. Impact strength variation along notch radius by increasing the HNT clay. 


\section{Results and discussion}

\subsection{Characterization of materials}

X-ray diffraction (XRD) was performed for the clay particles and clay particles filled epoxy to study the interlayer separation. The process was carried out with a scanning rate of $28 \mathrm{C} / \mathrm{min}$, with $\mathrm{CuK} \alpha$ radiation $(\lambda=$ $1.541 \AA$ ) operating at $30 \mathrm{kV}$ and $15 \mathrm{~mA}$ by the X-ray Diffractometer (Model: 2036E201; Rigaku, Ultima IV, Japan). Tensile tests were carried out using a DAK UTM machine at the crosshead speed of $1 \mathrm{~mm} / \mathrm{min}$ according to ASTM D-638. Impact testing was carried out using an Izod/charpy impact tester model machine and specimens prepared as per ASTM D-256. Hardness is tested by the barcoll hardness tester. Wear is tested on pin-on-disk set-up (DuCOM, TR-20-M26). Scanning electron microscope model is Hitachi make with field emission gun.

Figure 3 shows XRD plot between powder and hybrid nanocomposites reinforced with 1,2 and $3 \mathrm{wt} \%$ halloysite HNT clay. Halloysite HNT average crystal size is determined as $36 \eta \mathrm{m}$ by full width half mean of maximum peek obtained in plot.

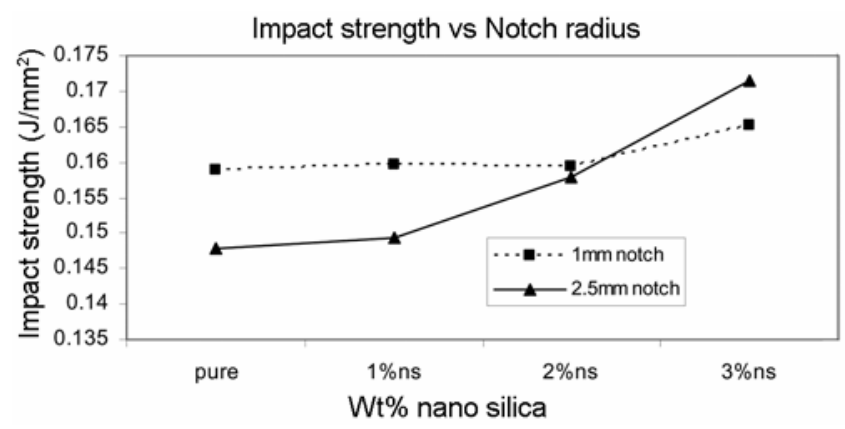

Figure 8. Impact strength variation along notch radius by increasing the silica.

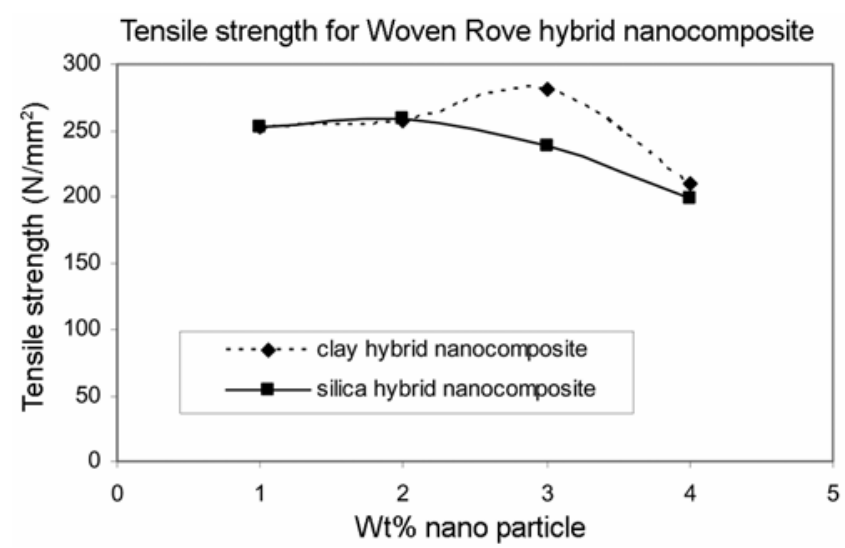

Figure 9. Tensile Strength by increasing the nanoparticle content.
Figure 4 shows the variation of the particle size with respect to the milling hours. It infers that there is a rapid decrease in the crystallite size from $4-25 \mathrm{~h}$. After $25 \mathrm{~h}$ there is no significant decrease in size but there is a gradual decrease. After $50 \mathrm{~h}$ of milling, the size decreased to $67 \eta \mathrm{m}$ from $100 \eta \mathrm{m}$.

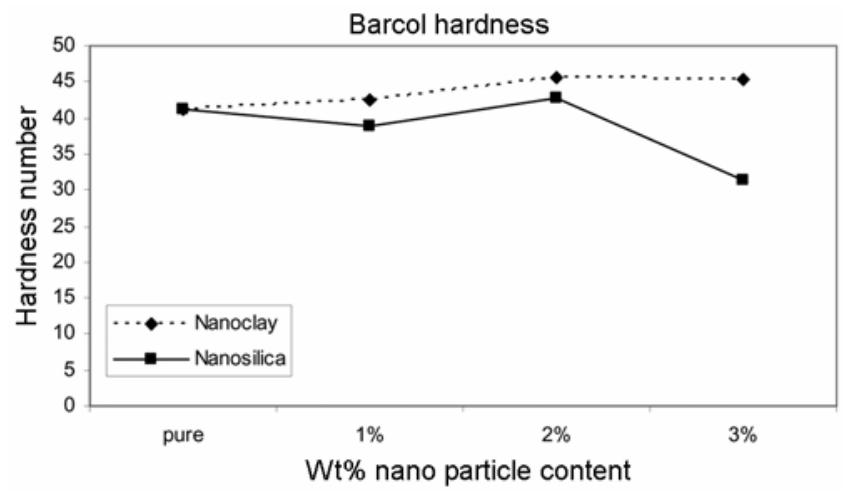

Figure 10. Barcoll hardness by increasing the nanoparticle content.

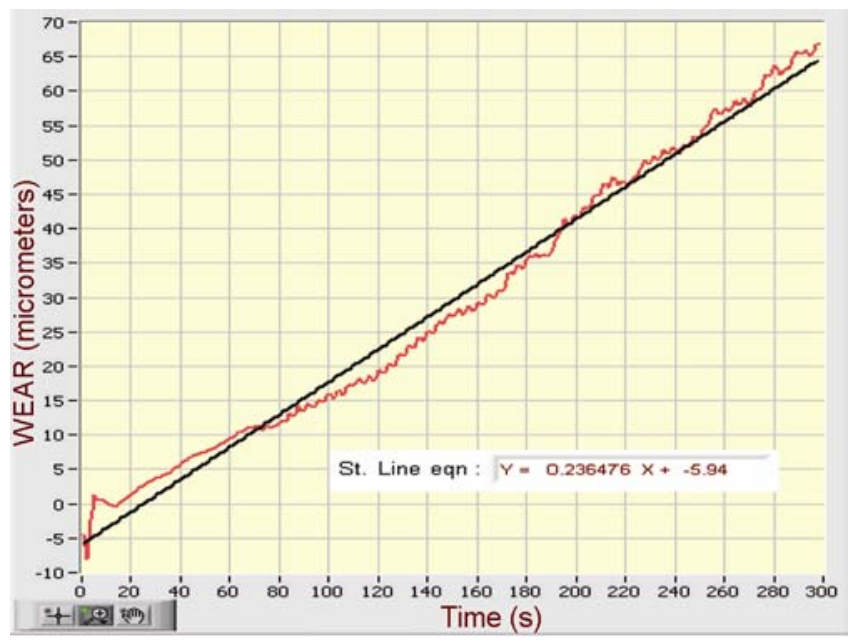

Figure 11. Wear of the pure samples at $25 \mathrm{~N}$ and travel distance of $1.81 \mathrm{~km}$

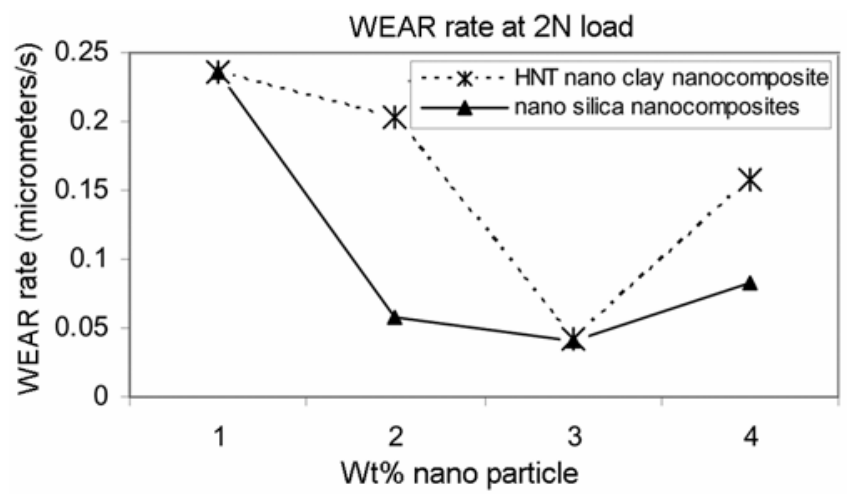

Figure 12. Wear rate by increasing the nanoparticle content. 

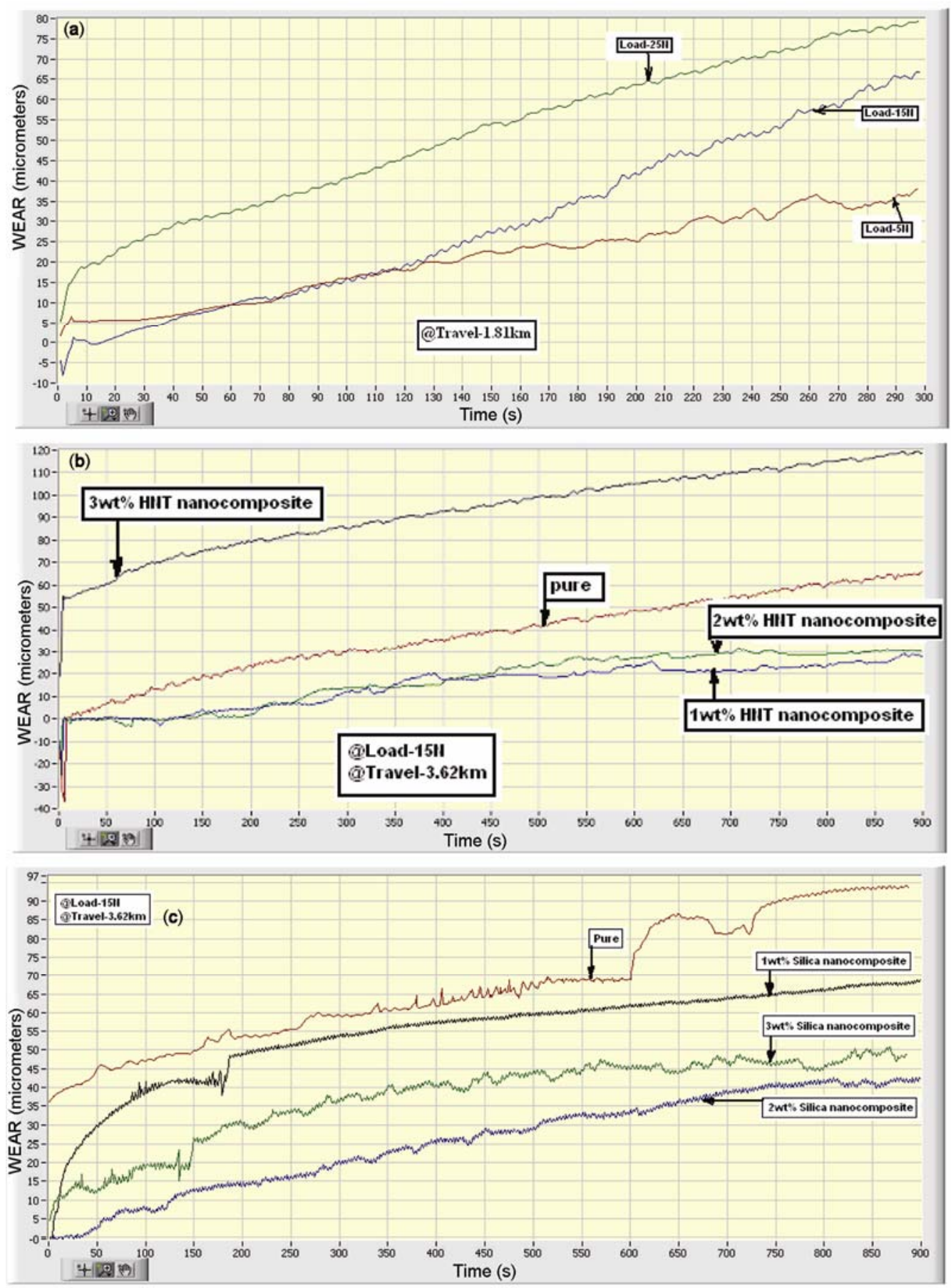

Figure 13. (a) Wear of pure polymer composite with load changes from 5-25 N. (b) Wear at load $5 \mathrm{~N}$ and track distance $3.64 \mathrm{~km}$ for pure, $1 \% \mathrm{HNT} \mathrm{NC}, 2 \% \mathrm{HNT}$ NC and 3\% HNT NC. (c) Wear at load $15 \mathrm{~N}$ and track distance $3.62 \mathrm{~km}$ for pure, $1 \% \mathrm{NS}, 2 \% \mathrm{NS}$ and $3 \% \mathrm{NS}$.

The SEM micrographs, shown in figure 5, reveal the nano tubular structure of nanoclay. Many agglomerates and a few particles can also be seen. The typical diameter and length/diameter ratio of HNTs are determined by measuring 10 randomly chosen nanotubes. The diameter ranges from $30-300 \eta \mathrm{m}$ and the length/diameter ratio is in the range of $3: 10$ and silica particle reinforced nanocomposites are as shown in figure 6.

\subsection{Mechanical properties}

Mechanical properties are analysed for the halloysite HNT clay reinforced epoxy hybrid composites. Impact strength improved from $0.158998 \mathrm{~J} / \mathrm{mm}^{2}$ to $0.203823 \mathrm{~J} /$ $\mathrm{mm}^{2}$ as shown in figure 7 . Impact strength improvement of $6-28 \%$ by reinforcing the HNT clay up to $2 \mathrm{wt} \%$ and of $20 \%$ by reinforcing to $3 \mathrm{wt} \%$ HNT clay can be 
obtained with $1 \mathrm{~mm}$ notch radius. Further impact strength improvement of $2-8 \%$ can be obtained by reinforcing the HNT clay up to $2 \mathrm{wt} \%$ but falls by reinforcing $3 \mathrm{wt} \%$ HNT clay with $2.5 \mathrm{~mm}$ notch radius. The above results conclude that higher notch radius give higher crack propagation and obtains less impact energy.

Mechanical properties are analysed for the silica reinforced epoxy hybrid nanocomposites. Impact strength improved from $0.158998 \mathrm{~J} / \mathrm{mm}^{2}$ to $0.16517 \mathrm{~J} / \mathrm{mm}^{2}$ as shown in figure 8 . Thus Impact strength improvement of $0 \cdot 3-4 \%$ by reinforcing the silica up to $3 \mathrm{wt} \%$ can be obtained with $1 \mathrm{~mm}$ notch radius and $0.9-6.6 \%$ by reinforcing the silica up to $2 \mathrm{wt} \%$. Further improvement of impact strength by reinforcing $3 \mathrm{wt} \%$ silica is $16 \%$ with $2.5 \mathrm{~mm}$ notch radius. The above results conclude that higher notch radius give higher crack propagation and obtains less impact energy.

Tensile strength improved from $252.7176 \mathrm{~N} / \mathrm{mm}^{2}$ to $281.73082 \mathrm{~N} / \mathrm{mm}^{2}$ as shown in figure 9. Thus tensile strength improves to $12 \%$ by reinforcing the HNT clay up to $2 \mathrm{wt} \%$, but falls to $209.19492 \mathrm{~N} / \mathrm{mm}^{2}$ by increasing the HNT clay. Tensile strength improved from $252.7176 \mathrm{~N} /$ $\mathrm{mm}^{2}$ to $258 \mathrm{~N} / \mathrm{mm}^{2}$ showing an improvement of silica up to $1 \mathrm{wt} \%$ and falls to $197.6501 \mathrm{~N} / \mathrm{mm}^{2}$ by increasing the silica.
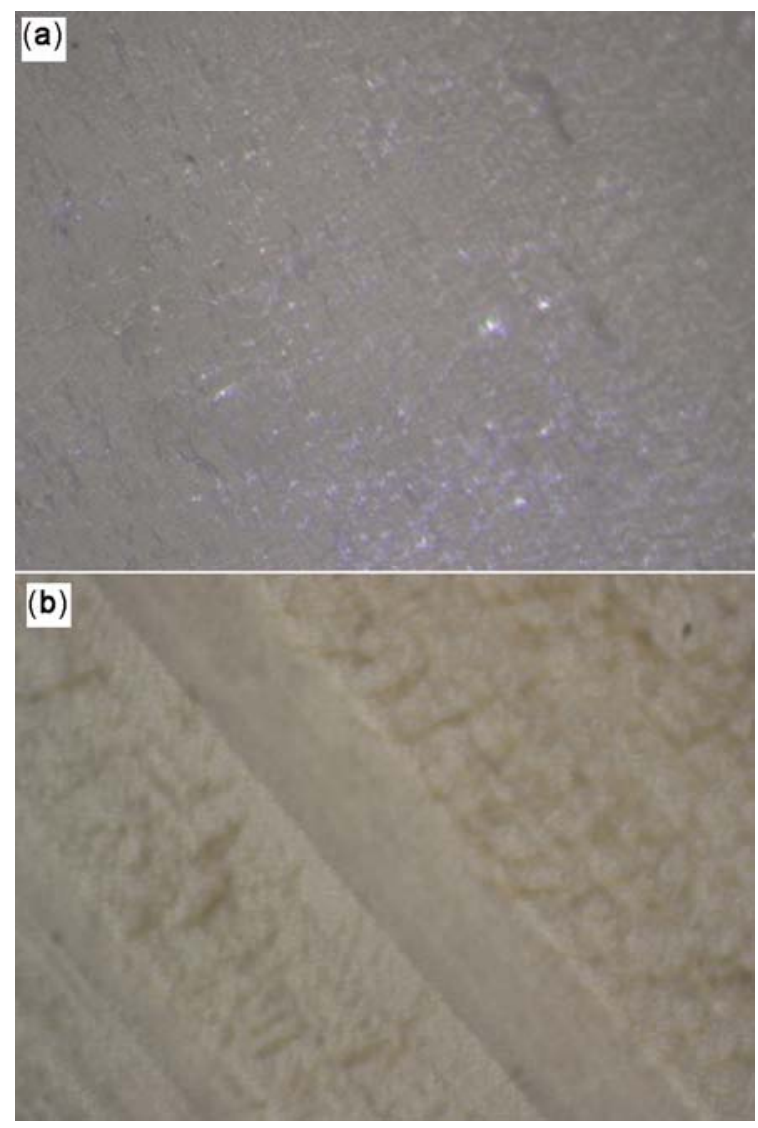

Figure 14. (a) pure epoxy sample at $100 \times$ magnification before wear. (b) Pure epoxy sample at $100 \times$ magnification after $3.62 \mathrm{~km}$ wear distance travel
The Barcoll hardness increased from $41-45$ as shown in figure 10 by increasing the HNT clay reinforcement and increased from $41 \cdot 1-42 \cdot 8$ by increasing the silica reinforcement up to $2 \mathrm{wt} \%$ and then falls to 31.4 by increasing the silica content.

\subsection{Tribological properties}

Wear graph displays acquired wear data and calculated wear rate by fitting a straight line function $y=m x+c$, where $m$ is the wear rate. Entire test time is considered to calculate wear rate. Wear rate of the pure samples at $25 \mathrm{~N}$ and travel distance of $1.81 \mathrm{~km}$ is 0.236476 and is shown in figure 11 .

The wear rate of neat epoxy decreased from 0.236476 to $0.041557 \mathrm{micrometers} / \mathrm{sec}$ at load $25 \mathrm{~N}$ and travel at $3.64 \mathrm{~km}$ as compared to $2 \%$ reinforced HNT clay nanocomposites and it increased 0.157897 micrometers/sec by reinforcing 3\% HNT clay as shown in figure 12 . The highest wear rate is seen with pure epoxy composite and lowest wear rate is at $2 \% \mathrm{HNT}$ clay reinforcement. The wear rate of neat epoxy decreased from 0.236476 to 0.040421 micrometers $/ \mathrm{sec}$ at load $25 \mathrm{~N}$ and travel at $3.64 \mathrm{~km}$ as compared to $2 \%$ reinforced silica nanocomposites and it increased $0.083357 \mathrm{micrometers} / \mathrm{s}$ by reinforcing $3 \%$ silica is shown in figure 12 . The highest wear rate is seen with pure epoxy composite and lowest wear rate is at $2 \%$ silica reinforcement. From this experiment we can conclude that, wear rate is inversely proportional to the hardness of the nanocomposites.

Figure 13 shows the wear in micro meters with abrading distance for different loads. It is evident from results that there is a linear trend of wear irrespective of the type of samples used. The pure epoxies exhibited considerably higher wear volume than nanoparticle reinforced nanocomposites. These nanocomposites are more wear resistant than the pure epoxy resin by increasing the load from $5-25 \mathrm{~N}$.

Microstructure of the pure composite wear specimens as shown in figures 14(a) and (b) shows maximum scratches on the wear surface. Pure composites have maximum scratches on the wear surfaces as compared with nanoparticle 1, 2 and $3 \mathrm{wt} \%$ reinforcement.

\section{Conclusions}

(I) Applied load and sliding velocity influence the wear process and is well reflected in the worn surface features as observed. The low load and speed combination shows tendency for the matrix adhering to the nanoparticles and lesser degree of debris formation.

(II) From the experimental investigation, it was found that the mechanical properties of the fiber reinforced composite show improvement with the inclusion of nanoparticles. The dry slide wear test results of hybrid 
nanocomposites show lower slide wear rates irrespective of the load/sliding speed when compared to pure composite.

(III) Addition of $2 \mathrm{wt} \%$ of HNT found $28 \%$ improvement of impact strength, $12 \%$ improvement in tensile strength, $4 \cdot 2 \%$ improvement in hardness and $490 \%$ improvement in wear rate.

(IV) Addition of $1 \mathrm{wt} \%$ of silica showed improvement of $6.6 \%$ in impact strength, $2.09 \%$ in tensile strength, $2 \%$ improvement of Barcoll hardness and $750 \%$ reduction in wear rate.

\section{Acknowledgement}

The authors are grateful to the support of the Naval Science Technological Laboratories, India, for providing experimental setup and guidelines and financial assistance.

\section{References}

Alexandre M and Dubois P 2000 Mater. Sci. Eng. Rep. 281

Bijwe J, Tewari U S and Vasudevan P 1989 Wear 132247

Biswas S K and Vijayan K 1992 Wear 158193

Chang H W 1983 Wear 8581

EI-Sayed A A, EI-Sherbiny M J, Abo-EI-Ezz A S and Aggag, G A 1995 Wear $\mathbf{1 8 4} 45$

Ferhat Gul and Mehmet Acilar 2004 Composite Sci. Technol. 641959

Friedrich K, Lu Z and Hager A M 1995 Wear 190139
Kishore Sampathkumaran P and Seetharamu S 1999 J. Reinforced Plast. Composit. 1855

Kuldiloke J 2002 Effect of ultrasound, temperature and pressure treatments on enzyme activity and quality indicators of fruit and vegetable juices (Berlin: Technische Universität) $\mathrm{Ph}$.D. Thesis

Lhymn C 1987 Wear 116343

Luo J J and Daniel I M 2003 Compos. Sci. Technol. 631607

Maiti P, Ray S S, Okamoto M, Yamada K and Ueda K 2002 Macromolecules 353104

Mallick PK 1993 Fibre reinforced composites: materials, manufacturing and design (New York: Marcel Dekker, Inc.) 2nd edn, p. 18

Ojima A, Usuki M, Ka Wasumi, Okada A, Fukushima Y, Urauchi T K and Kamigaito O 1993 J. Mater. Res. 81185

Okamoto M, Ray S S and Okamoto K 2003 Macromolecules 36 2355

Park C, Park O, Lim J and Kim H 2001 Polymer 427465

Ray S S, Yamada K, Ogami A, Okamoto M and Ueda K 2002a Macromol. Rapid Commun. 23943

Ray S S, Yamada K, Okamoto M and Ueda K 2002b Nano Lett. 21093

Suryanarayana C 2004 Mechanical alloying and milling (New York: Macel Dekker) pp. 15-30

Tripaty B S and Furey M J 1993 Wear 162-164 385

Vaia R A, Ishii H and Giannelis E P 1993 Chem. Mater. 51694

Velmurugan M 2009 J. Reinforced Plast. \& Composit. 2817

Vinson J R and Chou T 1975 Composite materials and their uses in structures (London: CRC Press)

Viswanath B, Verma A P and Kameswara Rao C V S 1992 Composite Sci. \& Technol. 4477

Yamada K, Maiti P, Okamoto M, Ueda K and Okamoto K 2002 Chem. Mater. 144654

Zhou et al 2007 Composites Sci. \& Technol. 672297 